\title{
Erratum to: The future of genomic medicine education in Africa
}

Geoffrey H. Siwo ${ }^{1,3,4^{*}}$, Scott M. Williams ${ }^{2}$ and Jason H. Moore ${ }^{1 *}$

\section{Erratum}

It has come to our attention that during the production of this article [1], the name of the first author, Geoffrey $\mathrm{H}$ Siwo, was incorrectly spelt as Siw. This has been corrected in the online version of the article.

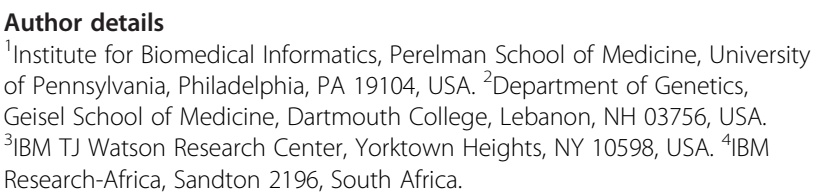

Published online: 03 August 2015

\section{References}

1. Siwo $\mathrm{GH}$, Williams SM, Moore $\mathrm{JH}$. The future of genomic medicine education in Africa. Genome Medicine. 2015;7:47.

\footnotetext{
*Correspondence: geoffrey@unitedgenomes.org; jhmoore@upenn.edu

${ }^{1}$ Institute for Biomedical Informatics, Perelman School of Medicine, University of Pennsylvania, Philadelphia, PA 19104, USA

Full list of author information is available at the end of the article
} 